\title{
Multiple modalities in insect warning displays have additive effects against wild avian predators
}

\author{
Bibiana Rojas $^{1}$ (D) - Johanna Mappes ${ }^{1} \cdot$ Emily Burdfield-Steel $^{1}$
}

Received: 7 November 2018 /Revised: 27 January 2019 / Accepted: 5 February 2019 / Published online: 26 February 2019

(C) The Author(s) 2019

\begin{abstract}
Allocation to different components of defence has been suggested as an explanation for the existence of multiple aposematic morphs in a single population. We tested whether there are trade-offs between warning colouration and chemical defence or whether these have an additive effect when combined, using blue tits (Cyanistes caeruleus) as predators and the polymorphic wood tiger moth (Arctia plantaginis) as prey. We used artificial edible models (with and without the moths' defensive fluids) with paper wings whose colour and pattern properties matched those of real moths. When the models were presented sans defensive fluids or when the fluids were presented without colour cues, we detected no differences in initial avoidance between the two morphs. However, when the colour and chemical cues were combined, differences emerged. White wings elicited higher latency to approach regardless of the defensive fluids applied on them. After approach, however, the defensive fluids of both morphs presented on moth models elicited higher latency to attack than a water control, hinting at a repellent odour. Fluids of white moths rendered lower amounts of prey eaten regardless of wing colour, while yellow moths' fluids provoked the highest occurrence of beak wiping behaviour. Our findings highlight the importance of accounting for interactive effects between different signal modalities, as these can create patterns not detectable when examined in isolation. Understanding these interactions is vital to determine how different components of multimodal warning displays provide protection at different stages of a predation event and, potentially, how multiple morphs can co-occur in a population.
\end{abstract}

\section{Significance statement}

There are many things that can stop a predator attacking a prey such as looking scary or smelling bad, but if a predator does take a bite, tasting bad can make the difference between life and death for the prey. When combined with bright conspicuous colours, both repellent odours and deterrent tastes (i.e. chemical defences) can help predators learn to avoid unprofitable prey. However, it is unclear whether it is really the sum of these visual and chemical signals that most effectively deters predators or whether one is more important than the other. Examining the effects of warning colour and chemical defence in white and yellow wood tiger moths on wild-caught birds, we show that neither aspect of the moths' defence in isolation is as effective for predator deterrence as the sum of both.

Keywords Multimodal signals $\cdot$ Tiger moth $\cdot$ Predator-prey interactions $\cdot$ Colour polymorphism $\cdot$ Chemical defences

Communicated by J. C. Choe

Electronic supplementary material The online version of this article (https://doi.org/10.1007/s00265-019-2643-6) contains supplementary material, which is available to authorized users.

Bibiana Rojas

bibiana.rojas@jyu.fi

1 Centre of Excellence in Biological Interactions, Department of Biology and Environmental Sciences, University of Jyväskylä, PO Box 35, 40001 Jyväskylä, Finland

\section{Introduction}

Aposematic organisms combine, often highly conspicuous, warning (visual) signals with secondary defences that warn predators about their unprofitability (Poulton 1890). These secondary defences can be behavioural, morphological or, most commonly, chemical (Ruxton et al. 2004) and exploit different sensory channels than the visual signals in the receivers (i.e. predators). Thus, the warning displays of aposematic organisms are assumed to be multimodal (Rowe and Guilford 1999; Rowe and Halpin 2013). 
Chemically defended prey bearing conspicuous warning signals (i.e. aposematic) are expected to have a uniform appearance because variation in warning signals is thought to interfere with predator avoidance learning. Thus, the co-occurrence of two or more warning signals within the same population is assumed to be selected against (Joron and Mallet 1998; Mallet and Joron 1999; Lindström et al. 2001a; Endler and Mappes 2004), unless variation in other traits can compensate for the expected fitness disadvantages for the less efficient signal bearers (reviewed in Briolat et al. 2018). Previous research suggests, for example, that highly unprofitable prey can afford to exhibit less efficient warning signals because they can survive predator attacks without incurring the costs of a more conspicuous visual signal (Leimar et al. 1986; Speed and Ruxton 2005). Thus, species exhibiting variation in more than one component (e.g. visual and chemical) of the multimodal warning display are ideal to investigate the possible adaptive value of each signal on its own, versus that of the interaction between the two, in predator deterrence.

The aposematic wood tiger moth, Arctia plantaginis, is polymorphic (white or yellow) for male hindwing colouration. The proportion of yellow and white morphs varies across its range (Hegna et al. 2015). Within Finland, where both morphs co-occur, there is evidence that they vary spatially, with Central Finland being predominantly white while Southern Finland shows an approximately 50/50 split between the two morphs (Nokelainen et al. 2014).

This visual signal is coupled with two types of chemical defences, one of which (hereafter, neck fluids) is particularly deterrent against birds (Rojas et al. 2017a). Experiments done with real moths and dummies, both in the lab and in the wild, indicate that yellow individuals tend to be less attacked by birds, suggesting that yellow is a better warning signal (Nokelainen et al. 2012, 2014; but see Rönkä et al. 2018), yet from those studies, it is not possible to infer which of the components of the warning display is conferring this advantage. Recent work where natural predators were exposed to the moths' chemical defences only (i.e. no colour information was provided) showed that the neck fluids of yellow males elicited longer latencies to approach by birds over time, implying better predator learning (Rojas et al. 2017a). This is at least partly due to the presence of methoxypyrazines (Burdfield-Steel et al. 2018b), chemical compounds frequently found in the chemical defences of aposematic insects (Rothschild et al. 1984; Moore et al. 1990; Wheeler et al. 2015), whose characteristic odour enhances bird learning of both visual and nonvisual cues (Guilford et al. 1987; Marples and Roper 1996; Rowe and Guilford 1996; Lindström et al. 2001b; Siddall and Marples 2011) and has been proven capable of inducing hidden innate wariness (e.g. Marples and Roper 1996; Rowe and Guilford 1996; Lindström et al. 2001b; Kelly and Marples 2004).

With these apparent advantages, it is puzzling that the yellow morph of these moths had not reached fixation, as colour polymorphism in aposematic species is assumed to be selected against (Endler 1988; Joron and Mallet 1998; Mallet and Joron 1999; Lindström et al. 2001a; Endler and Mappes 2004). However, recent research has shown that white males may persist due to their higher mating success under certain circumstances (Nokelainen et al. 2012; Gordon et al. 2015). An alternative explanation for the co-existence of these two morphs could be that white males invest more in their chemical defence to compensate for their less effective warning signal, a pattern of compensation that has been previously found between closely related species of poison frogs (Darst and Cummings 2006), and that such chemical defences are particularly efficient at eliciting rejection from a predator after attack. However, to disentangle the effects of the warning (visual) signal and the chemical defence on bird response, experiments are necessary where both components of the warning display are manipulated at the same time and where predator response to the combination of warning signal and chemical defence is assessed at the first encounter with the prey in a controlled manner (Rojas et al. 2018). Therefore, the possibility to isolate the visual signal from the chemical defence, as well as to produce different combinations of both, makes the wood tiger moth an excellent study system to better understand the role of each component of their multimodal warning display in anti-predator defence and elucidate whether there is a trade-off between the two types of defence or whether, instead, their effects on predator response are additive.

Here, we presented wild-caught bird model moths coated with either water or the real chemical defences of wood tiger moths to investigate whether the visual component of their warning display is effective against a predator on its own or whether its interaction with chemical defences provides the most effective protection. Because predators are more likely to detect, discriminate and memorise multimodal than unimodal signals (Rowe 1999), we predict that the combination between warning signal and chemical defence will act synergistically to elicit the strongest aversion by birds (Marples et al. 1994). We also address the question of whether the apparent advantage of yellow males against predators is due to their visual signal only or whether they ultimately benefit from the synergistic action of an efficient visual signal and a very repellent chemical defence. Finally, we test the hypothesis that the colour polymorphism in wood tiger moths can be maintained because the seemingly weak warning signal of white males is compensated by better (more deterrent) chemical defences after attack. 


\section{Material and methods}

\section{Study species and husbandry}

The wood tiger moth, Arctia plantaginis (formerly Parasemia plantaginis) (Rönkä et al. 2016), is an arctiid species with a wide Holarctic distribution (Hegna et al. 2015). Males can be polymorphic for hindwing colouration, which is either yellow or white (Fig. 1a) with variable amounts of melanisation (Nokelainen et al. 2012; Hegna et al. 2013). Females, on the other hand, present hindwings that vary continuously from yellow to red (Lindstedt et al. 2011), and have a similar pattern of melanisation as that of males. These hindwing colours are visible when the moths are resting on the vegetation (see Fig. 1a), and vision models have indicated that all these colours are conspicuous on a green background in the eyes of blue tits (Lindstedt et al. 2011; Nokelainen et al. 2012; Henze et al. 2018). Forewings are clearly visible for blue tits too, but their colouration does not differ between the two male morphs (Henze et al. 2018).

Fig. 1 a The two co-occurring morphs of the wood tiger moth in Finland. b Paper wings used during the experiment. $\mathbf{c}$

Reflectance curves of real (darkcoloured lines) and paper (lightcoloured lines) moths
Both males and females are considered aposematic, as their conspicuous colour patterns are coupled with distasteful chemical secretions (Lindstedt et al. 2011; Nokelainen et al. 2012; Rojas et al. 2017a; Burdfield-Steel et al. 2018a), which are of two types. One type ('neck fluid') is secreted from the prothoracic glands, and the other one (hereafter referred to as 'abdominal fluid') is released from the abdominal tract. Abdominal fluids can be released in response to subtle disturbances, whereas neck fluids are secreted only in response to the active 'squeezing' of the prothoracic glands (i.e. simulating a bird attack). These two defensive fluids have a different composition as per preliminary profiles obtained from gas chromatography (Rojas et al. 2017a). Notably, 2-sec-butyl-3methoxypyrazine, which is produced de novo (BurdfieldSteel et al. 2018b), is only present in the neck fluids and has been demonstrated to play a key role in bird deterrence (Rojas et al. 2017a). There is currently no evidence of any truly toxic substances in either defensive fluid; rather, the major compounds appear to be carboxylic acids (Rojas et al. 2017a). While preliminary data suggest differences in chemical
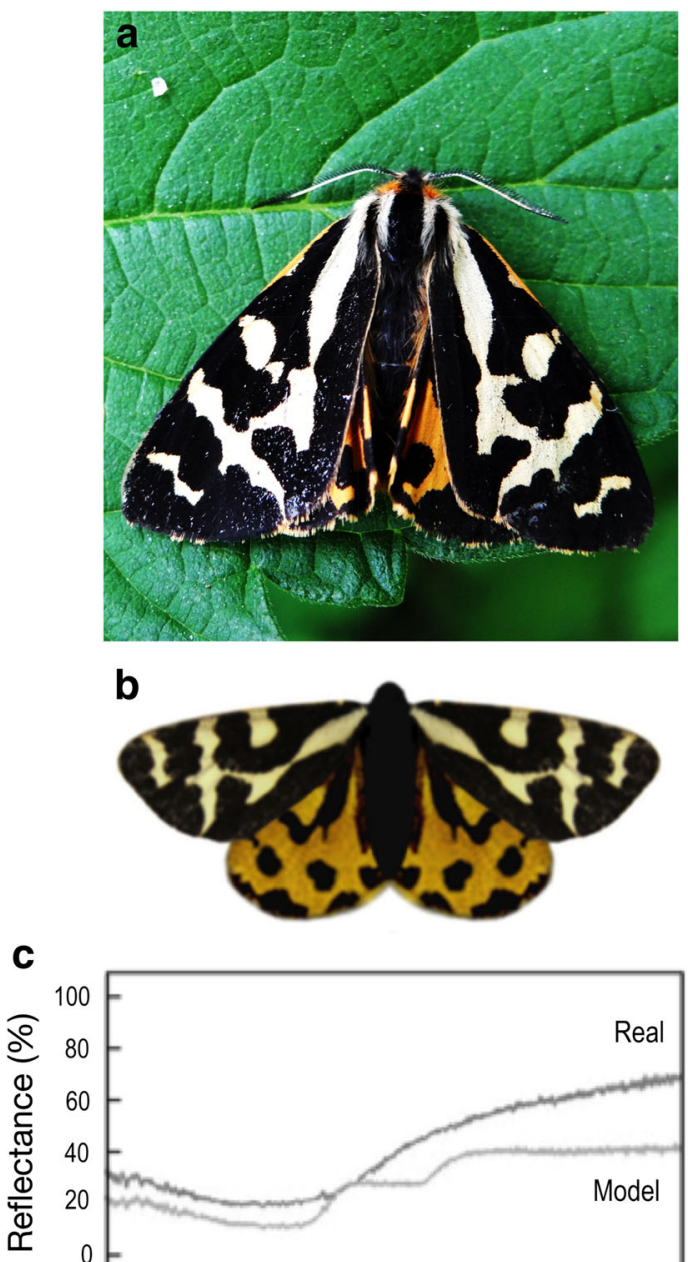

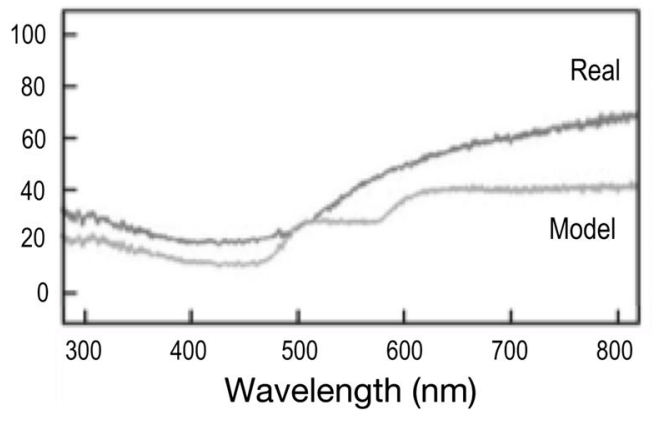

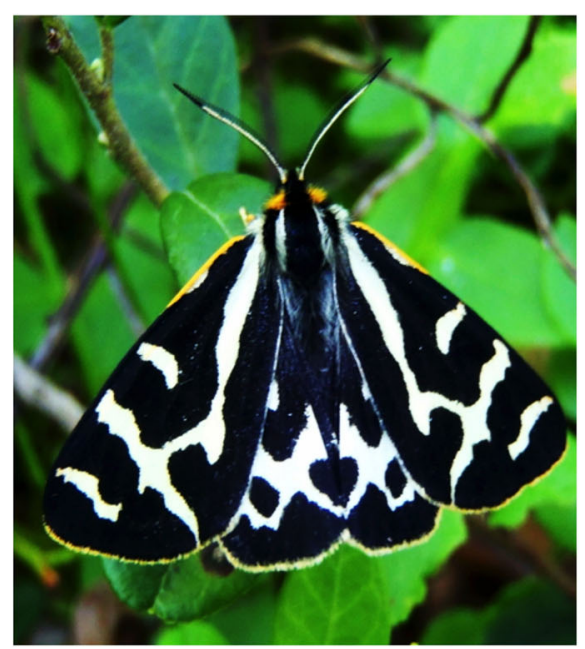
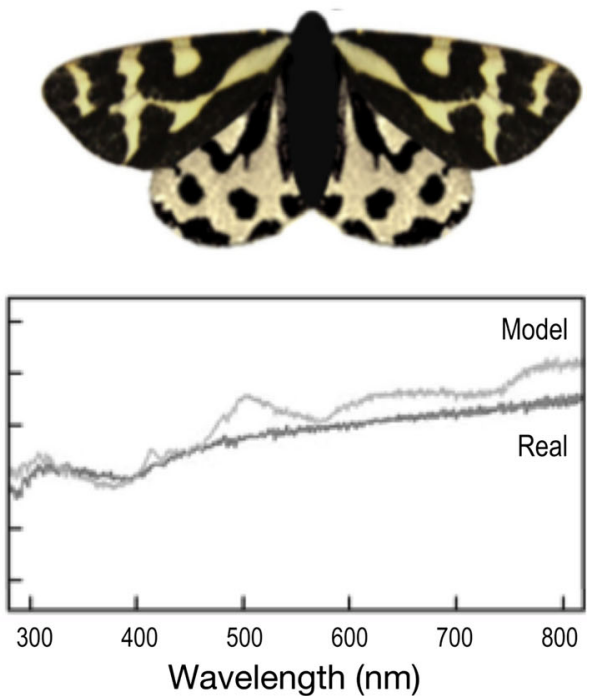
composition between morphs in the abdominal fluids (Lindstedt et al. in prep), evidence for morph differences in the neck fluids comes solely from behavioural assays (Rojas et al. 2017a).

Wood tiger moths are polyphagous and capital breeders, feeding only during the larval stage (Tammaru and Haukioja 1996). As adults, therefore, this species has a short lifespan (about 2 to 3 weeks), with only one generation per year. The individuals used in the present study were obtained from a laboratory stock reared at the University of Jyväskylä, where they are relatively easily bred under laboratory conditions. Larvae are kept on a diet consisting of dandelion (Taraxacum sp.) and lettuce leaves until pupation. After emergence, all individuals are sexed and their colour is recorded, and they are kept in a fridge at $7{ }^{\circ} \mathrm{C}$, where they remain until sampled for fluids.

\section{Collection of defensive fluids}

Fluids were sampled in summer 2014 from the laboratory stock at the University of Jyväskylä. Adult male moths were sampled between the day they eclosed and 10 days after eclosion, but most were sampled between 0 and 3 days post eclosion. Prior to sampling, all moths were sprayed with water. They were then given $1 \mathrm{~h}$ to drink and become active. Neck fluids were sampled by pinching the moth just below the thoracic glands with a pair of tweezers, stimulating the release of the fluid. The secreted fluid was then collected with $10 \mu \mathrm{l}$ glass capillaries, and its volume was measured. The fluids were then pooled into groups of three male moths of the same hindwing colour to provide enough fluids for replication and were diluted with distilled water to a volume of $50 \mu \mathrm{l}$. All samples were stored at $-80^{\circ} \mathrm{C}$ until use.

\section{Bioassays with birds}

As predators, 90 wild-caught blue tits (Cyanistes caeruleus) were used, which were trapped at a feeding site at Konnevesi Research Station and kept in captivity for approximately 5 days. Once trapped, all birds were housed individually in plywood cages with a daily light period of $11 \mathrm{~h}: 13 \mathrm{~h}$ (light:dark), fed on sunflower seeds, peanuts and a vitaminenriched food supplement and provided with fresh water ad libitum. After the experiment, all birds were aged, sexed (when possible) using plumage indicators and ringed for identification purposes before being released at the capture site. The experiment was conducted at Konnevesi Research Station, Finland, between January and March 2015. Wild birds were used with permission from the Central Finland Centre for Economic Development, Transport and the Environment and license from the National Animal Experiment Board (ESAVI/9114/04.10.07/2014) and the Central Finland Regional Environment Centre (VARELY/
294/2015) and were used according to the ASAB guidelines for the treatment of animals in behavioural research and teaching (ASAB 2017).

Experimental trials were conducted in masonite cages $(50 \mathrm{~cm} \times 50 \mathrm{~cm} \times 70 \mathrm{~cm}, w \times d \times h)$ containing a perch and a water bowl. The cage was lit with a light bulb (Exo Terra Repti Glo 10.0 UVB; see Waldron et al. 2017, supplementary material, for details on irradiance measurements from the experimental cages). Birds were observed through a meshcovered window in one of the cage's sides and filmed with a digital camera (Sony DSC-HX1). The experimental cages were placed in a dark room in order to avoid any potential disturbance provoked by the observer and to minimise any drafts or airflow that may influence odour cues. Before the experiment, birds were allowed a couple of hours in an experimental cage in order to familiarise them with the cage itself and with the feeding system. Food was offered through a hatch behind a visual barrier (Fig. 2a), which allowed us to record the exact moment at which food was detected by the bird. During this training phase, birds were offered sunflower seeds from a petri dish with a standard green background; during the assays, we used fake paper wings (see below) and a body made out of a pastry containing lard, flour and water. The pastry was cooked and then dyed with black food colouring to better resemble the appearance of the real moths. Model wings (Fig. 1b) were created with the software GIMP (2.8.16) from pictures of a real male wood tiger moth by replicating pictures of a forewing and a hindwing of a white male in order to ensure a symmetric pattern. Yellow models were made in the same way, using the same picture to keep the pattern constant, but modifying the hue to match the colour of a yellow male. Similarities between the actual moths and the paper models were corroborated with reflectance measurements as described in Rönkä et al. (2018) (Fig. 1c). The models used were printed on both sides with a laser printer (HP Color LaserJet CP2025) on waterproof (Rite in the Rain $\left.^{\circledR}\right)$ paper.

We tested 90 birds as follows: yellow wings and water (Yc, $N=15$ ), white wings and water (Wc, $N=15$ ), yellow wings and fluids from white males ( $\mathrm{Yw}, N=15)$, yellow wings and fluids from yellow males (Yy, $N=16$ ), white wings and fluids of yellow males (Wy, $N=15)$ and white wings and fluids of white males ( $\mathrm{Ww}, N=14$ ). Birds were assigned to each treatment evenly, trying to balance age and sex among the groups. Each assay was done with $25 \mu \mathrm{l}$ of a specific blend of the fluids of three males of the same colour (see above for details on fluid collection) or water; each blend was used twice (i.e. for two different birds), but the exact combination of three different mixtures was not repeated. Before the start of each assay, the $25 \mu$ l of fluids was coated on the pastry body, which was gently perforated with a needle to allow the absorption of some of the fluid, and then presented to the birds. The control models were coated in the same manner with $25 \mu$ of water 
Fig. 2 Illustration of the experimental set-up used to study bird response. a A bird prior to approaching the moth. b A bird prior to attacking the moth after approaching it
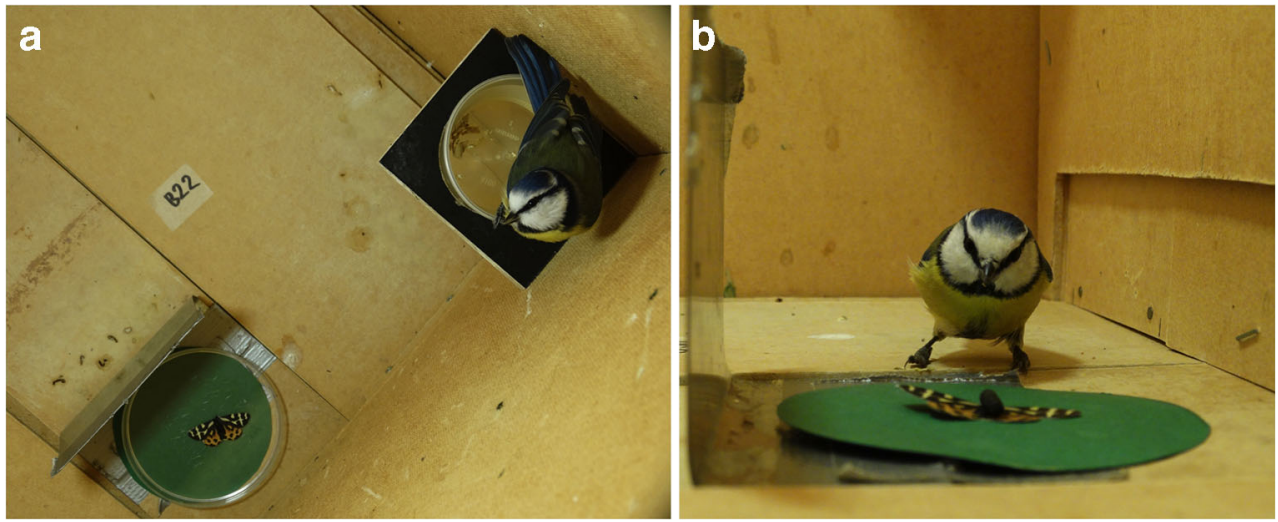

instead. Each bird was food deprived for a period of approximately $2 \mathrm{~h}$ in order to ensure motivation to feed.

An assay started by presenting the bird with the assigned model treatment placed on a green background (Fig. 2), as this is the most common background in which these moths are found in the wild (Nokelainen 2013) and because, in the eyes of a blue tit, both white and yellow males of $A$. plantaginis have a similar contrast against a green background (Henze et al. 2018). During the assay, two of the authors (BR and EBS) recorded the bird latency to approach the petri dish where the fake moth was offered (Fig. 2a) and the latency until the bird 'attacked' the moth (by grabbing it) after approaching the dish (Fig. 2b), which was taken as the moment at which birds tasted the fluids. We also counted the number of times the bird wiped its beak, which is a common behaviour after trying distasteful food (Evans and Waldbauer 1982; Skelhorn and Rowe 2009; Rowland et al. 2015). Likewise, we recorded by eye the proportion of the pastry body eaten by the bird to the closest $0.25,0.5,0.75$ or 1 fraction, in a maximum of $5 \mathrm{~min}$ (maximum trial duration). In the cases where the bird just tried it and ate much less than $25 \%$ of it, we recorded it as 0.10 , to differentiate it from the cases where the birds did not eat at all. In the same manner, when the bird ate almost all of the body, but some crumbs were left around during handling, we recorded it as 0.90 , to differentiate it from cases where the bird clearly ate all of the body, including the crumbs. The duration of the trial, taken as the time taken by the bird to finish the model body, was recorded in those cases where the birds ate all of the pastry. Each bird was tested only once, and with one type of fluid only. All birds were given a small mealworm at the beginning and end of the assay to confirm that they were hungry.

Data on bird response during a first encounter with the moths' chemical defences in the absence of any visual cues was taken from a previous study (Rojas et al. 2017b) in which the neck fluids were presented to birds on oat flakes (Rojas et al. 2017a). For this purpose, we used the data from the first trial in which birds were exposed to the chemical defences. Briefly, the same experimental set-up was used, with birds being offered three oats soaked with $25 \mu \mathrm{l}(\sim 8 \mu \mathrm{l}$ per oat) of neck fluids of either yellow or white moths. The oats were offered on a tray behind a visual barrier (see above), which ensured that we recorded the exact time at which the birds saw the oats. Because this dataset did not include information on latency to approach and beak wiping behaviour, only the latency to eat and the proportion of prey eaten were included in the analyses. The experimental cages and methods were otherwise the same (see details in Rojas et al. 2017a; Fig. 2a). We opted for this approach to prioritise bird welfare, as it meant catching ca. 40 fewer birds.

\section{Statistical analyses}

We first tested for the effect of the type of fluid (y, w, c) and colour morph $(\mathrm{Y}, \mathrm{W})$ on the probability that birds approached, attacked and ate the models using generalised linear models (GLMs) with a binomial distribution. We then analysed differences in bird latencies among treatments using a Cox mod$\mathrm{el}$, as the response variables were of the time-to-event type. The type of fluid and the interaction between the two were included as explanatory variables. The latencies until the bird approached and attacked the model (i.e. time to event) were used as response variables in separate models and included only the individuals that approached and attacked the models, respectively, using the package coxme (Therneau 2015). We then ran GLMs with a negative binomial distribution, including only those individuals that attacked the models, with frequency of beak wiping and the percentage of pastry body eaten as response variables, and the main effects of fluid and morph and the interaction between the two as explanatory variables; we accounted for variation in trial duration and a possible observer effect by including them in the model as covariates. In addition, to ensure that any observer variation did not influence between treatment differences, we tested the distribution of the treatments between the two observers. Model selection was done on the basis of differences in the Akaike information criteria (AIC). We started with models that included the main effects of morph (W, Y) and fluid (y, 
w, c), and the interaction between the two, and compared them with a model that included only the main effects. We report the results of the models with the lower AIC in each case. These and all analyses were done with R v.1.0.143 (R Core Team 2011) using the RStudio environment (RStudio Team 2015).

\section{Results}

Out of the 90 birds tested, 77 (85.6\%) approached the models, out of which $59(76.6 \%)$ attacked them and $19(24.6 \%)$ ate at least part of them (Table 1). Neither model colour nor type of fluid was a significant predictor of the probability of approaching, attacking or eating the models (Table 2).

When fluids were offered without any visual cues, we found no differences among treatments in latency to approach $($ morph $(\mathrm{Y})$ : estimate $\pm \mathrm{SE}=-0.341 \pm 0.413, z=-0.83$; morph $(\mathrm{W})$ : estimate $\pm \mathrm{SE}=-0.573 \pm 0.410, z=-1.40$; $p>0.05, N=39$ in both cases; Fig. 3b). Regardless of the fluids with which bodies were coated, and against our predictions, birds took longer to approach models with white wings (estimate $\pm \mathrm{SE}=0.467 \pm 0.235, z=1.99, p=0.047, N=77$; Fig. 3a). However, it seems likely that this effect is being driven by those models coated with defensive fluids of either morph, as when analysed separately, birds did not differ in their latency to approach yellow and white models coated with just water (estimate $\pm \mathrm{SE}=0.412 \pm 0.406 ; z=1.02 ; p>0.05$ ).

Once the birds approached the models, birds hesitated longer to attack those coated with defensive fluids (from both white and yellow moths) than those with water (fluid (y): estimate $\pm \mathrm{SE}=-1.120 \pm 0.498, z=-2.25, p=0.024$; fluid (w): estimate $\pm \mathrm{SE}=1.062 \pm 0.499, z=-2.13, p=0.033$, $N=59$; Fig. 4), regardless of the colour of the model's wings (estimate $\pm \mathrm{SE}=-0.234, z=-0.86, p>0.05, N=59$ ). No differences were found in bird response to fluids of white males versus fluids of yellow males (estimate $\pm \mathrm{SE}=0.027$ $\pm 1.027, z=0.08, p>0.05, N=59$ ).

Table 1 Number (and percentage, within brackets) of birds that attacked and ate the models of each of the six treatments used in this study, presenting either white (W) or yellow (Y) wings, and bodies coated with fluids of white males (w), fluids of yellow males (y) or water (c)

\begin{tabular}{|c|c|c|c|c|c|c|}
\hline & \multicolumn{6}{|l|}{ Treatment } \\
\hline & Wc & $\mathrm{Yc}$ & Wy & Yy & Ww & Yw \\
\hline$N$ & 13 & 13 & 14 & 14 & 12 & 11 \\
\hline Attack & $10(76.9)$ & $12(92.3)$ & $9(64.2)$ & $9(64.2)$ & $9(75.0)$ & $10(90.9)$ \\
\hline Eat & $5(38.5)$ & $5(38.5)$ & $3(21.4)$ & $2(14.3)$ & $1(8.3)$ & $3(27.3)$ \\
\hline
\end{tabular}

Only birds that approached $(N)$ were taken into account
The proportion of bodies eaten when coated with fluids of white moths was significantly lower than that of controls (estimate $\pm \mathrm{SE}=-2.364 \pm 1.143, z=-2.068, p=0.039$ ). No difference was found in the amount of prey eaten between bodies coated with fluids of yellow moths and controls (estimate \pm $\mathrm{SE}=-0.047 \pm 1.155, z=-0.041, p>0.05$ ), and while there was a trend towards bodies coated with white fluids being eaten less than those coated with yellow, this was not significant (estimate $\pm \mathrm{SE}=2.316 \pm 1.200, z=1.930, p=0.054$ ). There was no effect of wing colour on the amount of prey eaten (estimate $\pm \mathrm{SE}=0.770 \pm 0.951, z=0.810, p>0.05$; Fig. 5a).

The frequency at which birds wiped their beaks was not influenced by the colour of the models presented (estimate \pm $\mathrm{SE}=-0.326 \pm 0.502, z=-0.649, p>0.05, N=59)$ nor by the fluids with which they were coated (fluid w: estimate $\pm \mathrm{SE}=$ $-0.334 \pm 0.626, z=-0.532$; fluid y: estimate $\pm \mathrm{SE}=0.350 \pm$ $0.590, z=-0.595, p>0.05$ in both cases). We found an observer effect on beak wiping behaviour, but we consider this difference to not have affected our results given the even distribution of all treatments between the two observers $\left(\chi^{2}=\right.$ 6.73, $d f=5, p=0.242$ ). No observer effect was detected in any of the remaining response variables. Interestingly, when only the birds that ate some of the pastry $(N=19)$ were included in the analysis, we found that wiping behaviour was significantly more frequent in response to the fluids of yellow males (estimate $\pm \mathrm{SE}=1.492 \pm 0.600, z=2.485, p=0.013$; Fig. 6).

\section{Discussion}

Multimodal signals are prominent in animal communication across different taxa (Hölldobler 1999; Partan and Marler 1999; Cooper and Goller 2004; Ratcliffe and Nydam 2008; Bradbury and Vehrencamp 2011; Higham and Hebets 2013; Rojas et al. 2018). As such, many attempts have been made to identify their role(s) in various contexts, their mechanisms of sensory exploitation in the receiver(s) and their evolutionary pathways (Partan and Marler 1999; Rowe and Guilford 1999; Hebets and Papaj 2005; Partan 2013; Higham and Hebets 2013; Starnberger et al. 2014). The warning displays of aposematic organisms are a good example of multimodal signals, as they stimulate different sensory systems (e.g. visual and chemical) in predators (Rowe and Guilford 1999). However, despite being extensively documented, especially in insects, our understanding of their function in natural predator-prey interactions remains poor (Rowe and Halpin 2013; but see Marples et al. 1994, for a study using Japanese quails and their response to ladybird defences). Furthermore, most research has focused only on one of the components of these displays, while studies in which more than one component is considered are scarce (Rojas et al. 2018). 
Table 2 Effect of colour and type of fluid on the probability of approach (pApp), attack (pAtt) and eating (pEat) by birds $(N=90)$

\begin{tabular}{|c|c|c|c|c|c|c|c|c|c|}
\hline & \multicolumn{3}{|l|}{ Colour (Y) } & \multicolumn{3}{|l|}{ Fluid (w) } & \multicolumn{3}{|l|}{ Fluid (y) } \\
\hline & Estimate $\pm \mathrm{SE}$ & $z$ & $P$ & Estimate $\pm \mathrm{SE}$ & $z$ & $P$ & Estimate $\pm \mathrm{SE}$ & $z$ & $P$ \\
\hline pApp & $0.07 \pm 0.21$ & 0.31 & 0.75 & $0.08 \pm 0.26$ & 0.32 & 0.75 & $-0.04 \pm 0.26$ & -0.15 & 0.88 \\
\hline pAtt & $-0.11 \pm 0.21$ & -0.54 & 0.59 & $0.04 \pm 0.26$ & 0.17 & 0.86 & $-0.01 \pm 0.26$ & -0.04 & 0.97 \\
\hline pEat & $-0.04 \pm 0.21$ & -0.19 & 0.85 & $0.38 \pm 0.26$ & 1.44 & 0.15 & $0.32 \pm 0.26$ & 1.25 & 0.21 \\
\hline
\end{tabular}

The intercept includes colour (W (white)) and type of fluid (c (control))
In the present study, we addressed the function of the multimodal warning display in an aposematic, colour polymorphic, moth against natural bird predators. Our aim was to understand the role(s) of the different components of the display in predator deterrence and whether there was a trade-off or an additive effect between them. Our results indicate that the visual component alone, i.e. our models' wing colour, was indeed somewhat deterrent for the birds, as it elicited long latencies to attack. In particular, the fact that chemical defences in the absence of visual cues did not elicit longer latencies to approach than pure water shows the importance of the visual cue in deterring attack. Notably, we found that the combination of the visual and chemical cues elicited differences in the response of predators towards the two morphs that were not seen when the two modalities were tested separately. Moreover, our findings suggest not only that the moths' chemical defences have two components (odour and taste), but also that warning signals and chemical defences protect these polymorphic moths differently along the occurrence of a predation event and, possibly, at different spatial scales, i.e. long versus short distance.

\section{Predator deterrence at long distance}

Earlier studies on wood tiger moths have suggested that yellow is a better warning signal, as it appears to confer better protection from bird predators on its own (Nokelainen et al.
2012, 2014). Our results do not support the superiority of yellow as a warning signal over white, as we found that, when combined with the chemical defences of either morph, birds take longer to approach models with white wings than models with yellow wings. A possible way to explain this disagreement could be that in their 2012 study, Nokelainen et al. (2012) used real (either defrosted or live) moths, which means that bird response could have been influenced by remains of the chemical defences. This is not supported by the present study, as we found no interaction effect of colour and type of fluid on the latency to approach or to attack, in favour of yellow males. Instead, our results suggest that the combination of visual and chemical defences resulted in greater protection for the white morph. This discrepancy may result from other cues provided by the bodies of the moths, but not our models, such as additional odour cues. For example, the low number of birds that actually ate the prey might indicate that, although the artificial wings accurately resembled the appearance of the real moths, our models lacked some extra cues involved in rapid prey recognition. A previous study carried out in a similar setting showed that some birds were reluctant to attack and eat these models at the very first encounter, but the majority ate them after some training (Rönkä et al. 2018). Because we were interested in bird reaction to the first encounter with these prey, training was not a possibility within the scope of our study. Light environment may also play a role in bird
Fig. 3 Latency to approach in response to chemical fluids in the presence (a) and absence (b) of colour cues. Birds took longer to approach models with white wings, regardless of whether they were coated with fluids from yellow (Y) or white (W) males, or with pure water $(\mathrm{C})$. When no colour cues were presented, latency to approach did not differ among treatments. Boxes show the median and the 25 th and 75 th percentiles of data distribution. Vertical lines indicate data range and circles denote outliers

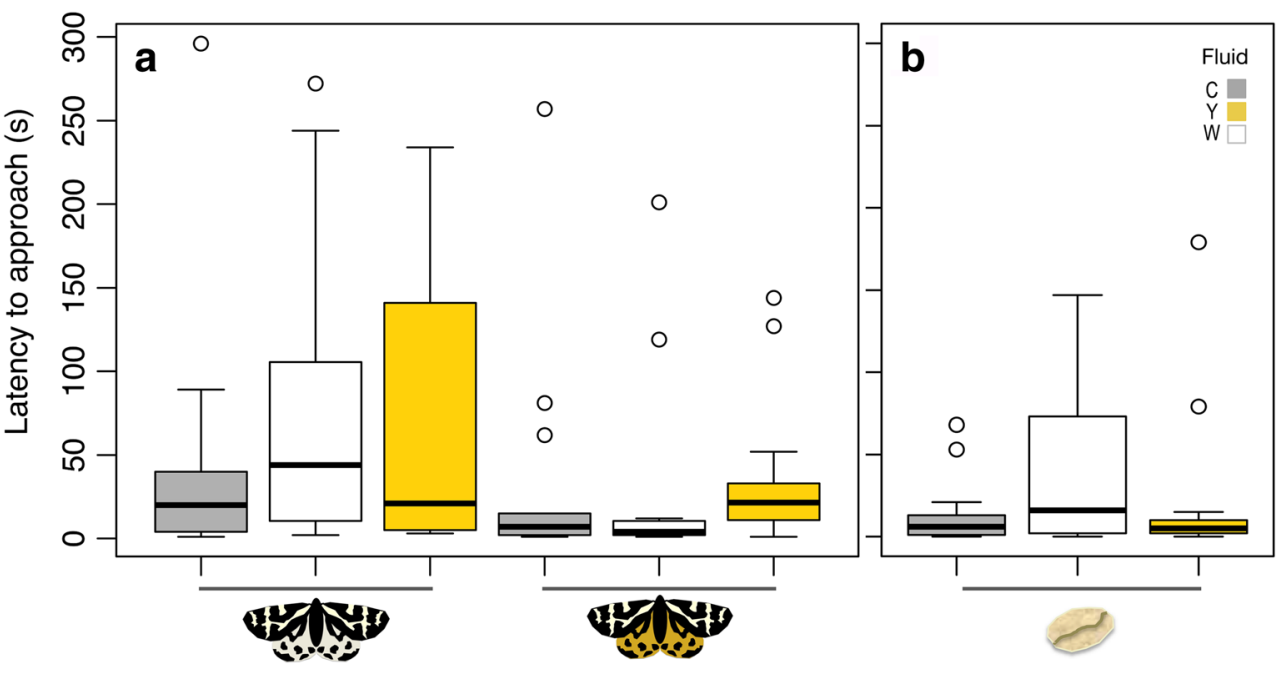


Fig. 4 Birds took longer to attack models coated with chemical defences of both yellow (Y) and white (W) males than those coated with pure water $(\mathrm{C})$, regardless of the colour of the models presented. Boxes show the median and the 25th and 75th percentiles of data distribution. Vertical lines indicate data range and circles denote outliers

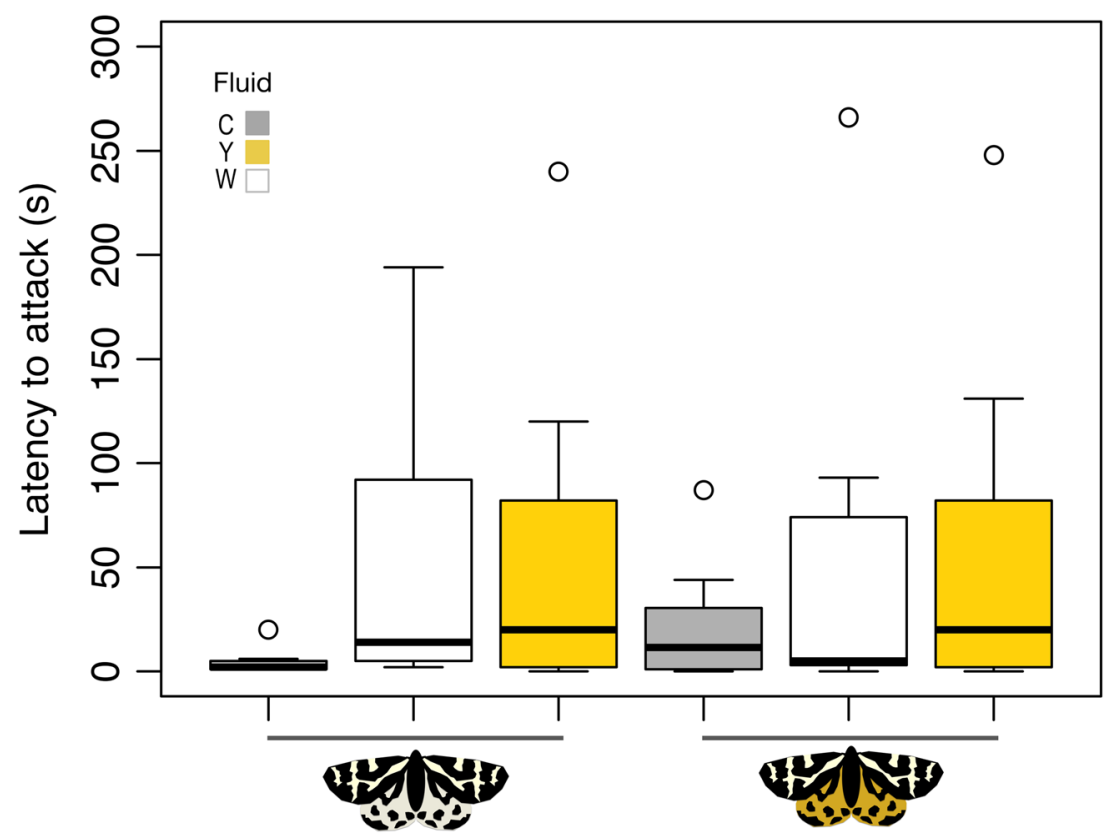

response to the visual cues. While broad-spectrum lights were used in this experiment, this may not accurately reflect the light conditions in the field, where these paper models have been most heavily used. For instance, despite the light bulbs used were emitting UV, the amount of UV at the cage floor, where the moths were offered to the birds, was virtually nonexistent (see Waldron et al. 2017, supplementary material). As work in both this (F. Rezende, O. Nokelainen and J. Mappes, unpublished) and other (Rojas et al. 2014) species has shown that there can be an interaction between colour pattern and light environment on predator response, further research on the role of light environment on bird's perception of visual signals may shed further light on the apparent mismatch between different experimental set-ups. These findings suggest that detection at long distances may elicit a different response in predators (based purely on colour) than detection at short distances, where the effect of the repulsive odour produced by the methoxypyrazines (Guilford et al. 1987) plays a more significant role (see below).

\section{Second and further lines of defence: protection after predator approach}

Birds hesitated for longer to attack a model after approaching it if it was coated with the defensive fluids of either white or

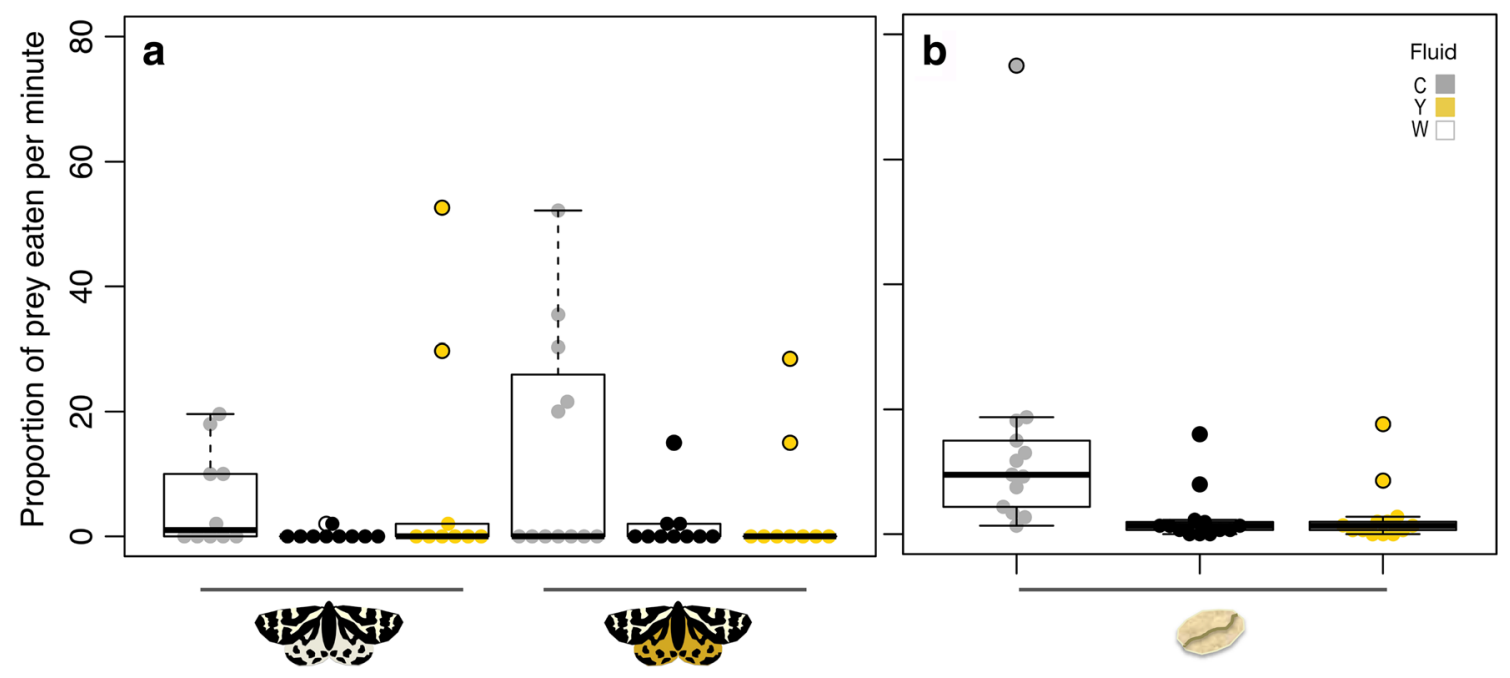

Fig. 5 Proportion of prey eaten in response to chemical fluids in the presence (a) and absence (b) of colour cues. Irrespective of the colour of the models presented, the chemical defences of white males rendered the lowest amounts of body eaten, indicating they taste worse. When no colour cues were presented, birds ate lower amounts of oats coated with fluids of both white and yellow males than of control oats. Boxes show the median and the 25th and 75th percentiles of data distribution. Vertical lines indicate data range and circles denote outliers 


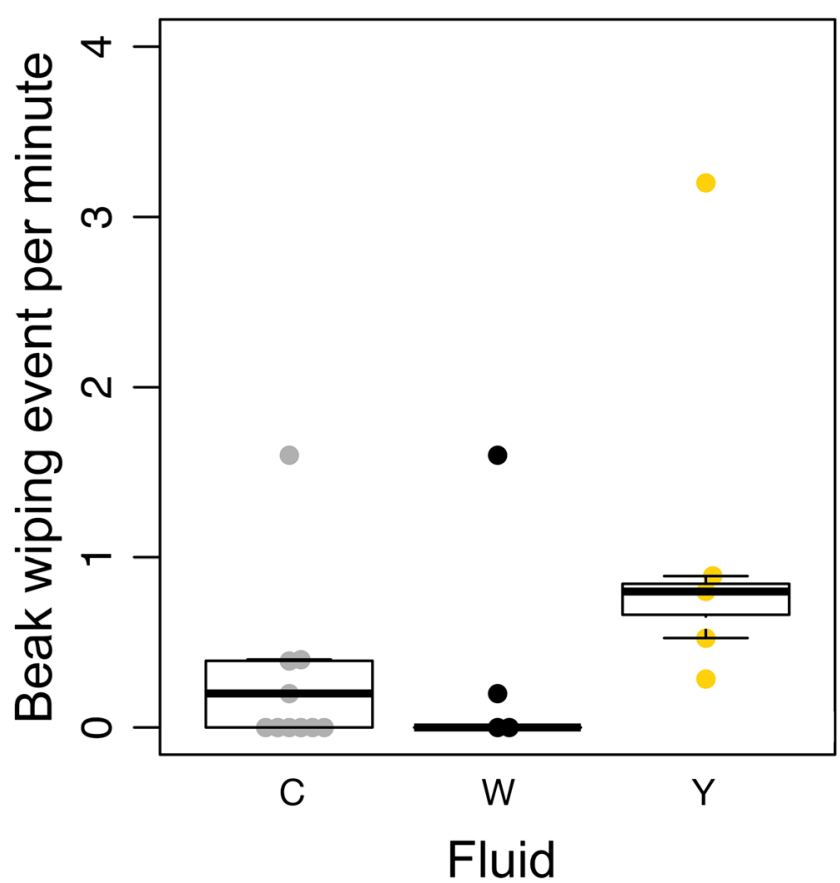

Fig. 6 Among birds that eat some of the pastry body, beak wiping behaviour, which is a sign of disgust, was significantly higher in response to the fluids of yellow males. Boxes show the median and the 25 th and 75 th percentiles of data distribution. Vertical lines indicate data range and circles denote outliers

yellow males. This reaction was independent of the wing colour presented, which indicates that at least during a first encounter with a moth, birds' decisions on when to attack were driven primarily by the moths' chemical defences. While these birds were wild caught and thus we have no information about their previous experience with aposematic prey, we believe this does not affect the validity of our results, as birds were evenly distributed across treatments.

The fact that birds hesitate for longer to attack the moth models coated with fluids without having even tasted them suggests that they are responding to a repulsive, or novel, odour. This agrees with our previous findings showing that neck fluids in the wood tiger moth contain pyrazines (Rojas et al. 2017a; Burdfield-Steel et al. 2018b), and that one of them (2-sec-butyl-3-methoxypyrazine) results in a lower amount of prey eaten and a tendency to hesitate longer before an attack when presented to birds in the absence of any visual cues (Rojas et al. 2017a). Pyrazine odours have long been known as a component capable of enhancing the effects of warning colouration (Rothschild et al. 1984; Guilford et al. 1987; Lindström et al. 2001b). This is because they enable smell/taste aversion in association with a particular visual stimulus (Rothschild et al. 1984; Marples and Roper 1996), creating 'hidden biases' (Rowe and Guilford 1996). Odours can discourage birds from trying out certain substances (Guilford et al. 1987), accelerate learning and improve memorisation when associated with colours (Barnea et al.
2004) and occasionally elicit a stronger response than visual cues (Roper and Marples 1997). Our results support the idea that birds rely on olfaction more often than it has been commonly assumed (Roper 1999; Steiger et al. 2008). This is an important point because the chemical composition of the neck fluids supports their classification as distasteful rather than toxic, as they do not appear to contain detectable amounts of any compounds known to be harmful to vertebrates. Indeed, while methoxypyrazines are usually referred to as warning odours, 2-sec-butyl-3-methoxypyrazine has been found to elicit disgust behaviours in blue tits (Rojas et al. 2017a), suggesting it is also distasteful. How this and the other methoxypyrazines present in the fluids, 2-isobutyl-3methoxypyrazine, may contribute to the apparent differences in odour and taste responses between the two morphs requires further investigation.

Beak wiping, a typical behavioural response that indicates disgust (Evans and Waldbauer 1982; Skelhorn and Rowe 2009; Rowland et al. 2015), was more frequent in response to fluids of yellow males, at least among those birds that actually ate some of the pastry. In contrast, when offered models coated with fluids of white moths, birds ate a significantly lower portion of the pastry body than when offered controls, regardless of the model wing colour, a difference not seen with the fluids of yellow moths. These findings point at a tight link between olfaction and taste that has proven difficult to tease apart. Indeed, it is known that the stimulation of olfactory receptors is likely to affect substantially the perception of taste, whereas the opposite is not true (Roper 1999). However, birds also have a remarkable ability to discriminate accurately between different tastes (Rowland et al. 2015). It could be argued that bird wiping does not relate to survival, but the elicitation of this behaviour may facilitate learning of the association of a particular colour or odour with the bad taste. Likewise, while a high proportion of prey eaten would mean the death of a real moth, in the context of this experiment, it provides valuable information on how far a bird would go with a distasteful prey before leaving it aside. In the wild, a predator that is not willing to eat more than a tiny portion of the moth may grant it the chance to survive an attack, which is indeed possible in this species (K. Rönkä and J. Mappes, unpublished). The low number of birds $(21.1 \%)$ that decided to eat the models, nevertheless, may reflect a particular caution (either innate or learned, which we cannot disentangle in the present study) towards aposematic prey. This is unlikely to be the result of a lack of motivation to eat, as birds were food deprived for $2 \mathrm{~h}$ prior to the beginning of the assays and were given a small-sized mealworm at the beginning and end of the assay to confirm that they were hungry. These findings highlight the importance of measuring several behavioural responses, instead of only one, as different variables may have different (and sometimes unclear) contributions to true fitness. 


\section{Implications for the maintenance of the hindwing colour polymorphism in wood tiger moths}

In the eyes of a blue tit, white and yellow males of A. plantaginis have a similar contrast against a green background (Henze et al. 2018). However, yellow males have been argued to have better warning signals in previous studies using either true moths (Nokelainen et al. 2012) or models similar to the ones used here which were deployed across different populations (Nokelainen et al. 2014). The former study was unable to disentangle the effect of colouration from that of its interaction with chemical defences; the latter, on the other hand, demonstrated that yellow individuals were protected in populations where the predator community was dominated by birds of the Paridae family, whereas white individuals were better protected in locations where prunellids were more common. Although dummy experiments can detect predator selection on phenotypes, they may over- or underestimate the fitness of each morph as (1) moths are able to survive bird attacks unharmed (K. Rönkä and J. Mappes, unpublished) probably due to their unpleasant odour and taste and (2) they do not take into account that moths may flee before they are attacked. Our results suggest, however, that once a predator has approached a moth, the odour of methoxypyrazines might deter them but, if the predator proceeds to attack, white moths might be more likely than yellow males to be released due to their bad taste (i.e. taste rejected). This means that white moths are protected at the last line of defence and may rely more on taste rejection by predators (Skelhorn and Rowe 2006a, b; Halpin and Rowe 2017), which could contribute to balancing the fitness of the two morphs in the wild.

\section{Multimodality and multicomponency in insect warning displays}

The evolution of multicomponent signals relies on how animals (predators, in this case) perceive unimodal versus multimodal stimuli (Rowe 1999). Differences in structure, transmission, permanence and detection of each component of a multicomponent, multimodal display can have particular effects on the perceptual system of the receiver (Bradbury and Vehrencamp 2011; Higham and Hebets 2013). However, multimodal signals ultimately "improve detectability, discriminability and memorability of signals by receivers" (Rowe 1999). All these benefits are a key for aposematic organisms, whose survival depends largely on predators learning (and then remembering) the association between their warning signals and secondary defences (Ruxton et al. 2018), and insects are no exception. Here, we show how some of the protection that is assumed to be obtained via predator learning can also take place during a first encounter (i.e. without previous learning) between natural predators and prey, and that it is crucial to consider the additive effects of multiple components when studying the function(s) of warning displays.

We are increasingly becoming aware that multimodal signalling comprising more than just two modalities is ubiquitous in the animal kingdom (de Luna et al. 2010; Higham and Hebets 2013; Starnberger et al. 2014; Rojas et al. 2018). Our study provides evidence that the multicomponent bimodal display of aposematic insects may elicit responses in predators that cannot be predicted by studying each signal mode in isolation. Likewise, these findings highlight the importance of accounting for chemical defence variation in studies on anti-predator strategies of aposematic species (Wheeler et al. 2015; Winters et al. 2018), especially those with a variable within-population appearance (Rojas et al. 2018). Finally, we advocate that chemical cues on their own can be a more powerful anti-bird defence than previously thought.

Acknowledgements Open access funding provided by University of Jyväskylä. We are grateful to Helinä Nisu for her priceless help with birds at Konnevesi Research Station and to the people at the greenhouse at the University of Jyväskylä for rearing the moths used in this experiment. Katja Rönkä designed the fake wings used for the models. Sebastiano De Bona and Janne Valkonen provided invaluable statistical advice. We are grateful to the members of the Plantaginis Journal Club and to the anonymous reviewers who gave thoughtful comments and suggestions that improved the manuscript.

Data availability statement The data used for this study will be available from the JYU data repository upon acceptance of the manuscript.

Funding information This study was funded by the Academy of Finland via the Centre of Excellence in Biological Interactions (Project No. 252411). BR is currently funded by the Academy of Finland (Academy Research Fellowship, Project No. 21000042021).

Open Access This article is distributed under the terms of the Creative Commons Attribution 4.0 International License (http:// creativecommons.org/licenses/by/4.0/), which permits unrestricted use, distribution, and reproduction in any medium, provided you give appropriate credit to the original author(s) and the source, provide a link to the Creative Commons license, and indicate if changes were made.

Publisher's note Springer Nature remains neutral with regard to jurisdictional claims in published maps and institutional affiliations.

\section{References}

ASAB (2017) Guidelines for the treatment of animals in behavioural research and teaching. Anim Behav 123:I-IX

Barnea A, Gvaryahu G, Rothschild M (2004) The effect of the odour of pyrazine and colours on recall of past events and learning in domestic chicks. In: Van Emden HF, Rothschild M (eds) Insect and bird interactions. Intercept Ltd., pp 205-216

Bradbury JW, Vehrencamp SL (2011) Principles of animal communication. Sinauer Associates Inc.

Briolat ES, Burdfield-Steel ER, Paul SC et al (2018) Diversity in warning coloration: selective paradox or the norm? Biol Rev. https://doi.org/ $10.1111 /$ brv. 12460 
Burdfield-Steel E, Brain M, Rojas B, Mappes J (2018a) The price of safety: food deprivation in early life influences the efficacy of chemical defence in an aposematic moth. Oikos 128:245-253

Burdfield-Steel E, Pakkanen H, Rojas B, Galarza JA, Mappes J (2018b) De novo synthesis of chemical defenses in an aposematic moth. J Insect Sci 18. https://doi.org/10.1093/jisesa/iey020

Cooper BG, Goller F (2004) Multimodal signals: enhancement and constraint of song motor patterns by visual display. Science 303:544 546

Darst CR, Cummings ME (2006) Predator learning favours mimicry of a less-toxic model in poison frogs. Nature 440:208-211

de Luna AG, Hödl W, Amézquita A (2010) Colour, size and movement as visual subcomponents in multimodal communication by the frog Allobates femoralis. Anim Behav 79:739-745

Endler JA (1988) Frequency-dependent predation, crypsis and aposematic coloration. Phil Trans R Soc Lond B 319:505-523

Endler JA, Mappes J (2004) Predator mixes and the conspicuousness of aposematic signals. Am Nat 163:532-547

Evans DL, Waldbauer GP (1982) Behavior of adult and naive birds when presented with a bumblebee and its mimic. Z Tierpsychol 59:247259

Gordon SP, Kokko H, Rojas B (2015) Colour polymorphism torn apart by opposing positive frequency-dependent selection, yet maintained in space. J Anim Ecol 84:1555-1564

Guilford T, Nicol C, Rothschild M, Moore BP (1987) The biological roles of pyrazines: evidence for a warning odour function. Biol J Linn Soc $31: 113-128$

Halpin CG, Rowe C (2017) The effect of distastefulness and conspicuous coloration on the post-attack rejection behaviour of predators and survival of prey. Biol J Linn Soc 120:236-244

Hebets EA, Papaj DR (2005) Complex signal function: developing a framework of testable hypotheses. Behav Ecol Sociobiol 57:197214

Hegna RH, Nokelainen O, Hegna JR, Mappes J (2013) To quiver or to shiver: increased melanization benefits thermoregulation, but reduces warning signal efficacy in the wood tiger moth. Proc R Soc B 280:20122812

Hegna RH, Galarza JA, Mappes J (2015) Global phylogeography and geographical variation in warning coloration of the wood tiger moth (Parasemia plantaginis). J Biogeogr 42:1469-1481

Henze MJ, Lind O, Mappes J, Rojas B, Kelber A (2018) An aposematic colour-polymorphic moth seen through the eyes of conspecifics and predators - sensitivity and colour discrimination in a tiger moth. Funct Ecol 32:1797-1809

Higham JP, Hebets EA (2013) An introduction to multimodal communication. Behav Ecol Sociobiol 67:1381-1388

Hölldobler B (1999) Multimodal signals in ant communication. J Comp Physiol A 184:129-141

Joron M, Mallet JL (1998) Diversity in mimicry: paradox or paradigm? Trends Ecol Evol 13:461-466

Kelly DJ, Marples NM (2004) The effects of novel odour and colour cues on food acceptance by the zebra finch, Taeniopygia guttata. Anim Behav 68:1049-1054

Leimar O, Enquist M, Sillen-Tullberg B (1986) Evolutionary stability of aposematic coloration and prey unprofitability: a theoretical analysis. Am Nat 128:469-490

Lindstedt C, Eager H, Ihalainen E, Kahilainen A, Stevens M, Mappes J (2011) Direction and strength of selection by predators for the color of the aposematic wood tiger moth. Behav Ecol 22:580-587

Lindström L, Alatalo RV, Lyytinen A, Mappes J (2001a) Strong antiapostatic selection against novel rare aposematic prey. Proc Natl Acad Sci 98:9181-9184

Lindström L, Rowe C, Guilford T (2001b) Pyrazine odour makes visually conspicuous prey aversive. Proc R Soc B 268:159-162
Mallet J, Joron M (1999) Evolution of diversity in warning color and mimicry: polymorphisms, shifting balance, and speciation. Annu Rev Ecol Syst 30:201-233

Marples NM, Roper TJ (1996) Effects of novel colour and smell on the response of naive chicks towards food and water. Anim Behav 51: $1417-1424$

Marples NM, van Veelen W, Brakefield PM (1994) The relative importance of colour, taste and smell in the protection of an aposematic insect Coccinella septempunctata. Anim Behav 48:967-974

Moore BP, Brown WV, Rothschild M (1990) Methylalkylpyrazines in aposematic insects, their hostplants and mimics. Chemoecology 1: $43-51$

Nokelainen O (2013) Many forms of the wood tiger moth (Parasemia plantaginis): selective heterogeneity favours polymorphic warning signals. Jyväskylä Studies in Biological and Environmental Science 259

Nokelainen O, Hegna RH, Reudler JH, Lindstedt C, Mappes J (2012) Trade-off between warning signal efficacy and mating success in the wood tiger moth. Proc R Soc B 279:257-265

Nokelainen O, Valkonen J, Lindstedt C, Mappes J (2014) Changes in predator community structure shifts the efficacy of two warning signals in Arctiid moths. J Anim Ecol 83:598-605

Partan SR (2013) Ten unanswered questions in multimodal communication. Behav Ecol Sociobiol 67:1523-1539

Partan S, Marler P (1999) Communication goes multimodal. Science 283 $1272-1273$

Poulton EB (1890) The colours of animals: their meaning and use, especially considered in the case of insects. Kegan Paul, Trench, Trubner

R Core Team (2011) R: a language and environment for statistical computing. R Foundation for Statistical Computing, Vienna, Austria. URL http://www.R-project.org/

Ratcliffe JM, Nydam ML (2008) Multimodal warning signals for a multiple predator world. Nature 455:96-99

Rojas B, Rautiala P, Mappes J (2014) Differential detectability of polymorphic warning signals under varying light environments. Behav Process 109(Pt B): 164-172

Rojas B, Burdfield-Steel E, Pakkanen H, Suisto K, Maczka M, Schulz S, Mappes J (2017a) How to fight multiple enemies: target-specific chemical defences in an aposematic moth. Proc R Soc B 284: 20171424

Rojas B, Burdfield-Steel E, Pakkanen H, et al (2017b) Bird data from how to fight multiple enemies: target-specific chemical defences in an aposematic moth. The Royal Society

Rojas B, Burdfield-Steel E, De Pasqual C et al (2018) Multimodal aposematic signals and their emerging role in mate attraction. Front Ecol Evol 6:93

Rönkä K, Mappes J, Kaila L, Wahlberg N (2016) Putting Parasemia in its phylogenetic place: a molecular analysis of the subtribe Arctiina (Lepidoptera): molecular phylogeny of Arctiina. Syst Entomol 41: 844-853

Rönkä K, De Pasqual C, Mappes J et al (2018) Colour alone matters: no predator generalization among morphs of an aposematic moth. Anim Behav 135:153-163

Roper TJ (1999) Olfaction in birds. In: Slater PJB, Rosenblat JS, Snowden CT, Roper TJ (eds) Advances in the study of behavior. Academic, pp 247-332

Roper TJ, Marples NM (1997) Odour and colour as cues for tasteavoidance learning in domestic chicks. Anim Behav 53:1241-1250

Rothschild M, Moore BP, Brown WV (1984) Pyrazines as warning odour components in the monarch butterfly, Danaus plexippus, and in moths of the genera Zygaena and Amata (Lepidoptera). Biol J Linn Soc 23:375-380

Rowe C (1999) Receiver psychology and the evolution of multicomponent signals. Anim Behav 58:921-931 
Rowe C, Guilford T (1996) Hidden colour aversions in domestic chicks triggered by pyrazine odours of insect warning displays. Nature 383 : $520-522$

Rowe C, Guilford T (1999) The evolution of multimodal warning displays. Evol Ecol 13:655-671

Rowe C, Halpin C (2013) Why are warning displays multimodal? Behav Ecol Sociobiol 67:1425-1439

Rowland HM, Parker MR, Jiang P et al (2015) Comparative taste biology with special focus on birds and reptiles. In: Doty RL (ed) Handbook of olfaction and gustation. Wiley, pp 957-982

RStudio Team (2015) RStudio: integrated development for R

Ruxton GD, Sherratt TN, Speed MP et al (2004) Avoiding attack: the evolutionary ecology of crypsis, warning signals and mimicry. Oxford University Press

Ruxton GD, Allen WL, Sherratt TN, Speed MP (2018) Avoiding attack: the evolutionary ecology of crypsis, aposematism, and mimicry. Oxford University Press

Siddall EC, Marples NM (2011) The effect of pyrazine odor on avoidance learning and memory in wild robins Erithacus rubecula. Curr Zool 57:208-214

Skelhorn J, Rowe C (2006a) Taste-rejection by predators and the evolution of unpalatability in prey. Behav Ecol Sociobiol 60:550-555

Skelhorn J, Rowe C (2006b) Avian predators taste-reject aposematic prey on the basis of their chemical defence. Biol Lett 2:348-350
Skelhorn J, Rowe C (2009) Distastefulness as an antipredator defence strategy. Anim Behav 78:761-766

Speed MP, Ruxton GD (2005) Warning displays in spiny animals: one (more) evolutionary route to aposematism. Evolution 59:2499-2508

Starnberger I, Preininger D, Hödl W (2014) From uni- to multimodality: towards an integrative view on anuran communication. J Comp Physiol A Neuroethol Sens Neural Behav Physiol 200:777-787

Steiger SS, Fidler AE, Valcu M, Kempenaers B (2008) Avian olfactory receptor gene repertoires: evidence for a well-developed sense of smell in birds? Proc Biol Sci 275:2309-2317

Tammaru T, Haukioja E (1996) Capital breeders and income breeders among Lepidoptera: consequences to population dynamics. Oikos 77:561-564

Therneau TM (2015) coxme: mixed effects Cox models. R package version 2-2

Waldron SJ, Endler JA, Valkonen JK et al (2017) Experimental evidence suggests that specular reflectance and glossy appearance help amplify warning signals. Sci Rep 7:257

Wheeler CA, Millar JG, Cardé RT (2015) Multimodal signal interactions in the ladybeetle, Hippodamia convergens, aposematic system. Chemoecology 25:123-133

Winters AE, Wilson NG, van den Berg CP, How MJ, Endler JA, Marshall NJ, White AM, Garson MJ, Cheney KL (2018) Toxicity and taste: unequal chemical defences in a mimicry ring. Proc R Soc B 285: 20180457 